\title{
Intraoperative pleural lavage cytology after lung resection as an independent prognostic factor for staging lung cancer
}

\author{
Yasushi Shintani, MD, PhD, ${ }^{\mathrm{a}}$ Mitsunori Ohta, MD, PhD, ${ }^{\mathrm{a}}$ Teruo Iwasaki, MD, PhD, ${ }^{\mathrm{a}}$ Naoki Ikeda, MD, PhD, ${ }^{\mathrm{a}}$ Takashi Kanou, MD, ${ }^{\mathrm{a}}$ \\ Emiko Tomita, MD, ${ }^{a}$ Katsuhiro Nakagawa, MD, PhD, ${ }^{a}$ Tsutomu Yasumitsu, MD, PhD, ${ }^{a}$ and Yuko Ohno, $\mathrm{PhD}^{\mathrm{b}}$
}

\begin{abstract}
Objective: Although malignant pleural effusion or dissemination is regarded as T4 per TNM classification of lung cancer, the prognostic significance in staging of pleural lavage cytologic examination remains undetermined. The purpose of this study was to clarify the utility of pleural lavage cytologic staging as a prognostic factor in patients with non-small cell lung cancer.
\end{abstract}

\begin{abstract}
Methods: In 1271 patients with lung cancer who underwent curative resection, intraoperative pleural lavage cytologic examination was performed at thoracotomy (first cytologic examination), immediately after pulmonary resection and mediastinal lymph node dissection (second cytologic examination), and after last washing of pleural cavity (third cytologic examination). Positive first cytologic result represented cytologic positive result before lung resection; positive second and third cytologic results were regarded as cytologic positive results after lung resection.
\end{abstract}

Results: Eighty-nine patients $(7.0 \%)$ had positive findings of pleural lavage cytologic examination before or after lung resection. Five-year survivals were $44.1 \%$ for patients with positive results before lung resection and $23.4 \%$ for patients with positive results after lung resection, both significantly worse than that for patients with negative results. Multivariate analyses revealed that positive lavage result after lung resection was an independent prognostic factor. We found significantly greater pleural recurrence among patients with positive pleural lavage cytologic results after lung resection than among those with negative results.

Conclusions: In addition to TNM classification, results of pleural lavage cytologic examination after lung resection should be considered when staging non-small cell lung cancer. Adjuvant systemic therapy may improve outcome for patients with positive results.

Earn CME credits at

http://cme.ctsnetjournals.org

Intraoperative pleural lavage cytologic examination (PLC) has been suggested as a possible prognostic factor for patients with non-small cell lung cancer (NSCLC). ${ }^{1-7} \mathrm{Al}-$ though there have been differences in the timing of instillation, volume, and type of carrier solution, a consistent finding is the uniformly poor prognosis of patients with positive results. ${ }^{8}$ We performed intraoperative PLC on more than 1200 patients at the same institution since 1985 and analyzed the relationship between positive cytologic findings and several pathologic factors. Malignant pleural effusion or pleural dissemination is regarded as T4 according to the TNM classification 9 ; however, the prognostic significance of PLC remains undetermined in terms of staging. The aim

\footnotetext{
From the Department of Thoracic Surgery, Osaka Prefectural Hospital Organization, Osaka Prefectural Medical Center for Respiratory and Allergic Disease, ${ }^{a}$ and the Department of Mathematical Health Science, Osaka University Graduate School of Medicine, ${ }^{\mathrm{b}}$ Osaka, Japan.

Received for publication April 25, 2008; revisions received Aug 12, 2008; accepted for publication Sept 12, 2008.

Address for reprints: Yasushi Shintani, MD, PhD, 3-7-1 Habikino, Osaka 583-8588,

Japan (E-mail: yasushishintani@aol.com).

J Thorac Cardiovasc Surg 2009;137:835-9

0022-5223/\$36.00

Copyright $\subset 2009$ by The American Association for Thoracic Surgery

doi:10.1016/j.jtcvs.2008.09.027
}

of this study was to clarify the utility of PLC as a prognostic factor for patients with NSCLC.

\section{MATERIALS AND METHODS}

From September 1985 to December 2005 in our institution, thoracotomy was performed in 1490 patients with pathologic stage IA to IIIA NSCLC. Because we excluded patients with effusion at the time of the operation, extreme adhesions, extreme chest wall invasion, or lack of curative resection, this study consisted of 1271 patients with lung cancer. All patients underwent intraoperative PLC at three times as previously reported ${ }^{4}$ : (1) at thoracotomy immediately on entering the pleural space (1st PLC), (2) at thoracotomy on completion of pulmonary resection and mediastinal lymph nodes (2nd PLC), and (3) at thoracotomy after the last washing of the pleural cavity with $5000 \mathrm{~mL}$ physiological saline solution before closing (3rd PLC). At each lavage, the pleural cavity was filled with $500 \mathrm{~mL}$ physiologic saline solution, which was aspirated into a glass bottle with heparin. About $400 \mathrm{~mL}$ of the supernatant of the lavage fluid was discarded after settlement, and the remainder was centrifuged at $1500 \mathrm{rpm}$ for 5 minutes. Cytologic examination was performed with the Papanicolaou method. Papanicolaou classes IV and $\mathrm{V}$ were regarded as positive cytologic findings.

Pathologic staging was assessed according to TNM staging (International Union Against Cancer), ${ }^{9}$ and the histologic type of the tumor was assessed according to the World Health Organization classification. ${ }^{10}$ Pathologic TNM classification, pleural status, differences in histologic type, and lymphatic and vascular invasions were examined. The Japanese Lung Cancer Society ${ }^{11}$ guidelines were used to classify pleural status into four groups as follows: p0, visceral pleura is not invaded by the tumor; p1, tumor has reached but not invaded through the visceral pleura; $\mathrm{p} 2$, tumor has invaded the visceral pleura but has not involved the parietal pleura; and $\mathrm{p} 3$, tumor has invaded the parietal pleura and chest wall.

Survival was defined as the interval in months between the day of operation and the date of death from any cause or of the last follow-up. Cancer recurrence was divided into three categories according to the sites of initial 


\section{Abbreviations and Acronyms}

CI $=$ confidence interval

NSCLC $=$ non-small cell lung cancer

PLC = pleural lavage cytologic examination

recurrence: locoregional, pleural, and distant. Pleural recurrence was defined as any recurrent disease within the hemithoracic pleura.

An institutional review board approved this retrospective study, and written informed consent for the surgical intervention was obtained from each patient. The $\chi 2$ test was used to assess the statistical significance of the differences according to PLC status and clinicopathologic factors. Survival curves were calculated according to the method of Kaplan and Meier, ${ }^{12}$ and the log-rank test was used to compare the survival curves. Variables related to survival were analyzed with the Cox proportional hazards regression model $^{13}$ (StatView version 5.0; SAS Institute, Inc, Cary, NC).

\section{RESULTS}

Patient clinicopathologic characteristics are shown in Table 1. The median follow-up was 5.7 years. Eighty-nine patients, $7.0 \%$ of the study group $(n=1271)$, had positive findings on PLC before or after lung resection. As shown in Table 2, 67 patients $(5.3 \%)$ had positive PLC results at thoracotomy (1st PLC). Thirty-two patients $(2.5 \%)$ had positive results at thoracotomy on completion of pulmonary resection and mediastinal lymph nodes (2nd PLC), at thoracotomy after the last washing of the pleural cavity before closing (3rd PLC), or both. Positive 1st PLC result was regarded as a positive PLC result before lung resection, whereas positive 2nd and 3rd PLC results were regarded as positive PLC results after lung resection. Ten patients had positive PLC results both before and after lung resection.

There were significant differences between patients with negative and positive PLC results before lung resection in pathologic stage, pleural invasion, $T$ status, and vascular invasion (Table 3). Furthermore, significant differences were observed between patients with negative and positive PLC results after lung resection in pathologic stage, $\mathrm{T}$ status, and vascular invasion (Table 4). The 5-year survivals were $44.1 \%(95 \%$ confidence interval $[\mathrm{CI}] 31.2 \%-57.0 \%)$ for patients with positive PLC results before lung resection and $21.9 \%(95 \%$ CI $7.6 \%-34.2 \%)$ for patients with positive PLC results after lung resection, both of which were significantly worse than the $58.3 \%(95 \%$ CI $55.2 \%-61.4 \%)$ survival for patients with negative PLC results (Figures 1 and 2). To evaluate PLC result as a prognostic factor, multivariate analyses were performed with variables regarded as clinical prognostic factors for patients with NSCLC. These analyses revealed that a positive PLC result after lung resection was an independent prognostic factor (Table 5). Age, pathologic stage, lymphatic invasion, and vascular invasion were also independent prognostic factors.

We found recurrences in 384 of 1182 patients $(32.5 \%)$ with negative PLC results, in 32 of 67 patients $(47.8 \%)$
TABLE 1. Patient characteristics $(n=1271)$

\begin{tabular}{lr}
\hline \multicolumn{1}{c}{ Characteristic } & No. \\
\hline Sex & \\
Male & 870 \\
Female & 401 \\
Pathologic stage & \\
IA & 393 \\
IB & 335 \\
IIA & 44 \\
IIB & 232 \\
IIIA & 267 \\
Histologic type & \\
Adenocarcinoma & 699 \\
Squamous cell carcinoma & 398 \\
Others & 174 \\
\hline
\end{tabular}

with positive PLC results before lung resection, and in 20 of 32 patients $(62.5 \%)$ with positive PLC results after lung resection. The 5-year disease-free survivals were $36.9 \%(95 \%$ CI $22.2 \%-51.6 \%)$ for patients with positive PLC results before lung resection, $34.1 \% \quad(95 \%$ CI $14.3 \%-54.9 \%$ ) for patients with positive PLC results after lung resection, and $38.1 \%(95 \%$ CI $34.0 \%-42.2 \%)$ for patients with negative PLC results. There was no significant difference among these survivals. Recurrence patterns among patients with positive PLC results are shown in Table 6 . We found a significantly higher rate of pleural recurrence in patients with positive PLC results after lung resection than among with those with negative PLC results.

\section{DISCUSSION}

The survival in the group with positive PLC results was significantly lower than that in the group with negative PLC results, indicating that intraoperative PLC is a useful technique for estimating the prognosis of patients with lung cancer, as has been previously suggested. ${ }^{1-7,14}$ In agreement with the findings of Enatsu and colleagues, ${ }^{15}$ positive PLC results after lung resection had a greater impact on

TABLE 2. Results of pleural lavage cytologic examination

\begin{tabular}{|c|c|c|c|c|c|}
\hline \multicolumn{3}{|c|}{ Cytologic examination } & \multirow[b]{2}{*}{$\begin{array}{c}\text { Total } \\
\text { patients }\end{array}$} & \multicolumn{2}{|c|}{ Results } \\
\hline $\begin{array}{c}\text { 1st } \\
\text { PLC }\end{array}$ & $\begin{array}{l}\text { 2nd } \\
\text { PLC }\end{array}$ & $\begin{array}{c}\text { 3rd } \\
\text { PLC }\end{array}$ & & $\begin{array}{c}\text { Before } \\
\text { resection }\end{array}$ & $\begin{array}{c}\text { After } \\
\text { resection }\end{array}$ \\
\hline Negative & Negative & Negative & 1182 & Negative & Negative \\
\hline Positive & Negative & Negative & 57 & Positive & Negative \\
\hline Positive & Negative & Positive & 2 & Positive & Positive \\
\hline Positive & Positive & Negative & 4 & Positive & Positive \\
\hline Positive & Positive & Positive & 4 & Positive & Positive \\
\hline Negative & Negative & Positive & 4 & Negative & Positive \\
\hline Negative & Positive & Negative & 13 & Negative & Positive \\
\hline Negative & Positive & Positive & 5 & Negative & Positive \\
\hline
\end{tabular}

$P L C$, Pleural lavage cytologic result; 1 st $P L C$, at thoracotomy immediately on entering pleural space; 2nd PLC, after completion of pulmonary resection and mediastinal lymph node dissection; $3 r d P L C$, after last washing of pleural cavity before closing. 
TABLE 3. Clinicopathologic characteristics of patients with positive results of pleural lavage cytologic examination before lung resection

\begin{tabular}{|c|c|c|c|c|}
\hline Factor & $\begin{array}{l}\text { Positive } \\
(n=67)\end{array}$ & $\begin{array}{l}\text { Negative } \\
(n=1204)\end{array}$ & $\begin{array}{c}\text { Total } \\
(\mathrm{n}=\mathbf{1 2 7 1})\end{array}$ & $\begin{array}{c}P \\
\text { value }\end{array}$ \\
\hline Sex & & & & .2969 \\
\hline Male & $42(4.8 \%)$ & 828 & 870 & \\
\hline Female & $25(6.2 \%)$ & 376 & 401 & \\
\hline Pathologic stage & & & & .0397 \\
\hline I & $29(4.0 \%)$ & 699 & 728 & \\
\hline II & $17(6.2 \%)$ & 259 & 276 & \\
\hline IIIA & $21(7.9 \%)$ & 246 & 267 & \\
\hline Histologic type & & & & .1408 \\
\hline Adenocarcinoma & $44(6.3 \%)$ & 655 & 699 & \\
\hline $\begin{array}{l}\text { Squamous cell } \\
\text { carcinoma }\end{array}$ & $14(3.5 \%)$ & 384 & 398 & \\
\hline Other & $9(5.2 \%)$ & 165 & 174 & \\
\hline $\begin{array}{c}\text { Pathologic pleural } \\
\text { involvement }\end{array}$ & & & & $<.0001$ \\
\hline $\mathrm{p} 0$ & $26(3.4 \%)$ & 731 & 757 & \\
\hline p1 & $10(4.5 \%)$ & 212 & 222 & \\
\hline $\mathrm{p} 2$ & $18(14.7 \%)$ & 105 & 123 & \\
\hline p3 & $13(7.7 \%)$ & 156 & 169 & \\
\hline Pathologic $\mathrm{T}$ status & & & & .0002 \\
\hline $\mathrm{T} 1$ & $10(2.1 \%)$ & 469 & 479 & \\
\hline $\mathrm{T} 2$ & $43(6.8 \%)$ & 592 & 635 & \\
\hline $\mathrm{T} 3$ & $14(8.9 \%)$ & 143 & 157 & \\
\hline Pathologic N status & & & & .0937 \\
\hline No & $36(4.5 \%)$ & 772 & 808 & \\
\hline N1 & $13(5.4 \%)$ & 229 & 242 & \\
\hline $\mathrm{N} 2$ & $18(8.1 \%)$ & 203 & 221 & \\
\hline $\begin{array}{c}\text { Lymphatic invasion } \\
\qquad(\mathrm{n}=1192)\end{array}$ & & & & .1751 \\
\hline Positive & $42(6.0 \%)$ & 655 & 697 & \\
\hline Negative & $21(4.2 \%)$ & 474 & 495 & \\
\hline $\begin{array}{c}\text { Vascular invasion } \\
\qquad(\mathrm{n}=1193)\end{array}$ & & & & .0048 \\
\hline Positive & $47(6.9 \%)$ & 639 & 686 & \\
\hline Negative & $16(3.2 \%)$ & 491 & 507 & \\
\hline
\end{tabular}

Values represent numbers of patients.

survival than did positive PLC results before lung resection. Multivariate analyses also revealed that a positive PLC result after lung resection as an independent prognostic factor was as significant as established prognostic factors, including $\mathrm{T}$ status and $\mathrm{N}$ status. The 5-year survival after surgery was $23.4 \%$ for patients with positive PLC results after lung resection, whereas the 5-year survivals for patients with stages IIIA and IIIB were $31.4 \%$ and $21.7 \%$, respectively. Kotoulas and associates ${ }^{16}$ reported that a positive PLC result after lung resection is a T4 element, upgrading the stage to IIIB. Thus PLC after lung resection as an addition to the TNM classification is recommended to help determine the prognosis of patients with NSCLC.

Buhr and colleagues ${ }^{3}$ reported that pleural lavage was done before lung resection to determine whether tumor cells were disseminated into the pleural cavity. ${ }^{3}$ Exfoliation of tu-
TABLE 4. Clinicopathologic characteristics for patients with positive results of pleural lavage cytologic examination after lung resection

\begin{tabular}{|c|c|c|c|c|}
\hline Factor & $\begin{array}{l}\text { Positive } \\
(\mathbf{n}=\mathbf{3 2})\end{array}$ & $\begin{array}{l}\text { Negative } \\
(n=1239)\end{array}$ & $\begin{array}{c}\text { Total } \\
(\mathbf{n}=\mathbf{1 2 7 1})\end{array}$ & $\begin{array}{c}P \\
\text { value }\end{array}$ \\
\hline Sex & & & & .6728 \\
\hline Male & $23(2.6 \%)$ & 847 & 870 & \\
\hline Female & $9(2.2 \%)$ & 392 & 401 & \\
\hline Pathologic stage & & & & .6991 \\
\hline I & $16(2.2 \%)$ & 712 & 728 & \\
\hline II & $8(2.9 \%)$ & 268 & 276 & \\
\hline IIIA & $8(3.0 \%)$ & 259 & 267 & \\
\hline Histologic type & & & & .9785 \\
\hline Adenocarcinoma & $18(2.6 \%)$ & 681 & 699 & \\
\hline $\begin{array}{l}\text { Squamous cell } \\
\text { carcinoma }\end{array}$ & $10(2.5 \%)$ & 388 & 398 & \\
\hline Other & $4(2.3 \%)$ & 170 & 174 & \\
\hline $\begin{array}{c}\text { Pathologic pleural } \\
\text { involvement }\end{array}$ & & & & .1674 \\
\hline $\mathrm{p} 0$ & $14(1.8 \%)$ & 743 & 757 & \\
\hline $\mathrm{p} 1$ & $6(2.7 \%)$ & 216 & 222 & \\
\hline $\mathrm{p} 2$ & $4(3.3 \%)$ & 119 & 123 & \\
\hline p3 & $8(4.7 \%)$ & 161 & 169 & \\
\hline Pathologic T status & & & & .0016 \\
\hline $\mathrm{T} 1$ & $3(0.6 \%)$ & 476 & 479 & \\
\hline $\mathrm{T} 2$ & $21(3.3 \%)$ & 614 & 635 & \\
\hline $\mathrm{T} 3$ & $8(5.1 \%)$ & 149 & 157 & \\
\hline Pathologic N status & & & & 6299 \\
\hline No & $18(2.2 \%)$ & 790 & 808 & \\
\hline N1 & $8(3.3 \%)$ & 234 & 242 & \\
\hline N2 & $6(2.7 \%)$ & 215 & 221 & \\
\hline $\begin{array}{l}\text { Lymphatic invasion } \\
\qquad(\mathrm{n}=1192)\end{array}$ & & & & .2886 \\
\hline Positive & $21(3.0 \%)$ & 676 & 697 & \\
\hline Negative & $10(2.0 \%)$ & 485 & 495 & \\
\hline $\begin{array}{l}\text { Vascular invasion } \\
\qquad(\mathrm{n}=1193)\end{array}$ & & & & .0468 \\
\hline Positive & $24(3.5 \%)$ & 662 & 686 & \\
\hline Negative & $7(1.4 \%)$ & 500 & 507 & \\
\hline
\end{tabular}

mor cells through subpleural lymphatics and vessels to the pleural space has been reported to be a cause of positive PLC results before lung resection. ${ }^{5,7}$ There was a significant relationship between positive PLC results before lung resection and pleural invasion, making PLC at thoracotomy useful for estimation of pleural invasion. Similarly to the findings of Nakagawa and associates ${ }^{14}$ p2 was more frequently observed than $\mathrm{p} 3$ in patients with positive PLC results before lung resection, suggesting that tumor that has reached but not invaded through the visceral pleura is important for cancer cells to desquamate into the pleural space. In our study, 32 of 67 patients $(47.8 \%)$ with positive PLC results before lung resection had recurrence, and 3 of these $(9 \%)$ had carcinomatous pleuritis, a higher rate of recurrence in the pleural cavity than was seen among patients with negative PLC results $(2 \%)$. 


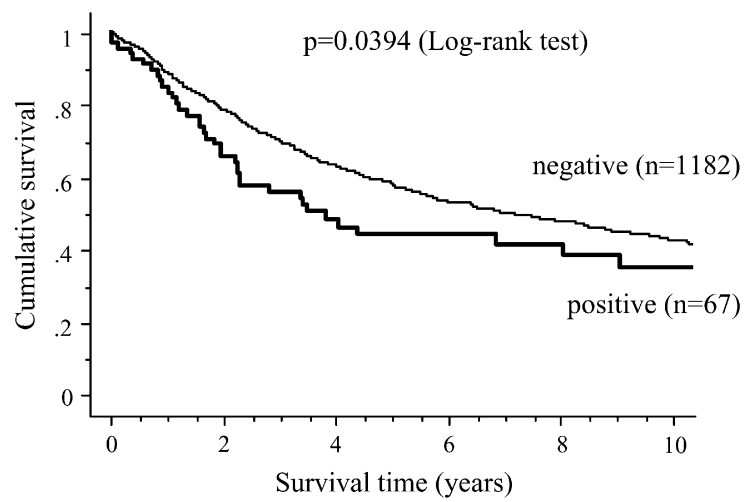

Patients at risk

\begin{tabular}{lllllll}
\hline Negative & 1182 & 832 & 546 & 354 & 227 & 179 \\
Positive & 67 & 41 & 23 & 18 & 13 & 9 \\
\hline
\end{tabular}

FIGURE 1. Survival curves for patients with positive versus negative results of pleural lavage cytologic examination before lung resection.

Buhr and colleagues ${ }^{3}$ also reported that PLC after lung resection indicated whether surgical manipulation had led to exfoliation of tumor cells into the pleural cavity. Kotoulas and associates ${ }^{16}$ reported that the main causes of positive PLC results after lung resection are the exfoliation of cancer cells into the pleural cavity from infiltrated mediastinal lymph nodes and the spreading of the cancer cells of infiltrated mediastinal lymph nodes as a result of surgical manipulations during the mediastinal dissections. We also found significant differences in pathologic stage, $T$ status, and vascular invasion between patients with positive and negative PLC results after lung resection, indicating that surgical manipulation of a large tumor with vessel invasion might lead to exfoliation and release of cancer cells into the pleural cav-

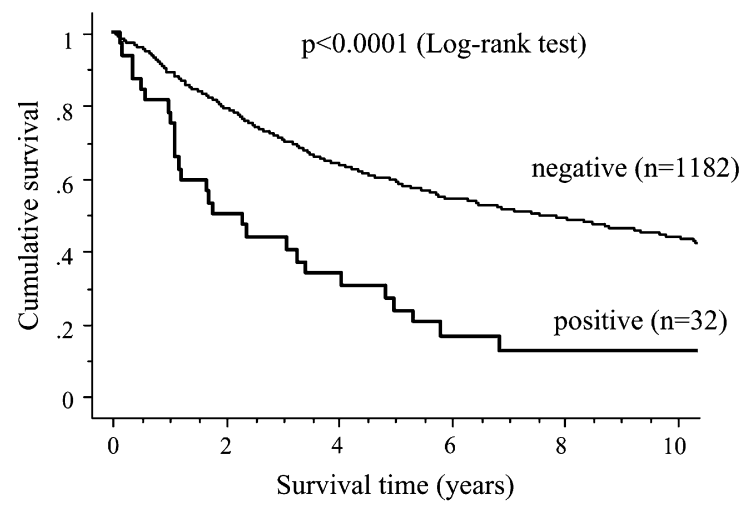

Patients at risk

\begin{tabular}{lllllll}
\hline Negative & 1182 & 832 & 546 & 354 & 227 & 179 \\
Positive & 32 & 16 & 10 & 5 & 3 & 3 \\
\hline
\end{tabular}

FIGURE 2. Survival curves for patients with positive versus negative results of pleural lavage cytologic examination after lung resection.
TABLE 5. Multivariate analysis of potential prognostic factors

\begin{tabular}{|c|c|c|c|}
\hline Variable & $\begin{array}{l}\text { Hazard } \\
\text { ratio }\end{array}$ & $\begin{array}{c}95 \% \text { Confidence } \\
\text { interval }\end{array}$ & $\begin{array}{c}P \\
\text { value }\end{array}$ \\
\hline \multicolumn{4}{|l|}{ Age } \\
\hline$\geq 65$ y vs $<65$ y & 1.895 & $1.592-2.256$ & $<.0001$ \\
\hline \multicolumn{4}{|l|}{ Pathologic stage } \\
\hline IIIA vs I & 2.438 & $1.969-3.019$ & $<.0001$ \\
\hline II vs I & 1.626 & $1.305-2.027$ & $<.0001$ \\
\hline \multicolumn{4}{|l|}{ Histologic type } \\
\hline $\begin{array}{l}\text { Other vs adenocarcinoma } \\
\text { or squamous }\end{array}$ & 1.113 & $0.936-1.323$ & .2245 \\
\hline \multicolumn{4}{|l|}{ Lymphatic invasion } \\
\hline Positive vs negative & 1.270 & $1.041-1.551)$ & .0188 \\
\hline \multicolumn{4}{|l|}{ Vascular invasion } \\
\hline Positive vs negative & 1.562 & $1.269-1.921$ & $<.0001$ \\
\hline \multicolumn{4}{|l|}{ PLC before resection } \\
\hline Positive vs negative & 1.072 & $0.753-1.525$ & .7003 \\
\hline \multicolumn{4}{|l|}{ PLC after resection } \\
\hline Positive vs negative & 2.313 & $1.516-3.531$ & .0001 \\
\hline
\end{tabular}

ity. Thirty-two patients showed positive PLC results after resection of lung and mediastinal lymph nodes; 17 of these had negative results after the last washing of the pleural cavity, whereas the remaining 15 patients showed positive PLC results even after the last washing (Table 2). The 5-year survivals were $29.4 \%$ for patients with positive PLC results before the last washing and $15.2 \%$ for patients with positive PLC results after the last washing. The frequency of recurrence in the pleura was greater among patients with positive PLC results after lung resection than in other groups. These data suggest that a positive PLC result after lung resection is indicative of cancer cells in the pleural cavity, which in turn may result in local recurrence at pleura.

The Japanese Clinical Oncology Group ${ }^{17}$ conducted a randomized trial to determine the efficacy of intraoperative intrapleural hypotonic cisplatin treatment for patients with positive PLC results. Survivals were not significantly different between the treated and control groups. Satoh and colleagues ${ }^{18}$ analyzed recurrence patterns in patients with positive PLC results and reported that $72 \%$ had distant metastasis. ${ }^{18}$ We found distant metastasis in 36 of patients with

TABLE 6. Recurrence of disease in patients with positive and negative results of pleural lavage cytologic examination

\begin{tabular}{lccc}
\hline & \multicolumn{2}{c}{ Positive } & \\
\cline { 2 - 3 } Recurrence & $\begin{array}{c}\text { Before resection } \\
(\mathbf{n}=\mathbf{6 7})\end{array}$ & $\begin{array}{c}\text { After resection } \\
(\mathbf{n}=\mathbf{3 2})\end{array}$ & $\begin{array}{c}\text { Negative } \\
(\mathbf{n}=\mathbf{1 1 8 2})\end{array}$ \\
\hline Total & 32 & 20 & 384 \\
Pleural & $3(9 \%)$ & $5(25 \%)$ & $7(2 \%)$ \\
Distant & $24(75 \%)$ & $11(55 \%)$ & $324(84 \%)$ \\
Locoregional & $5(16 \%)$ & $4(20 \%)$ & $53(14 \%)$ \\
\hline By $\chi^{2}$ test, $P<.05$ for positive results before resection versus negative results and \\
$P<.0001$ for positive results after resection versus negative results.
\end{tabular}


positive PLC results $(69.2 \%)$ who had recurrence, indicating that a positive PLC result is a sign of systemic disease. Therefore curative resection followed by adjuvant systemic therapy may be necessary to improve outcome for patients with positive PLC results. Furthermore, we should verify intraoperative intrapleural treatment for patients with NSCLC who have positive PLC results after lung resection to reduce the rate of pleural recurrence.

In conclusion, we have shown that a positive PLC result after lung resection can be used as an independent prognostic factor for staging NSCLC, together with such established prognostic factors as pathologic $\mathrm{T}$ status and $\mathrm{N}$ status. In addition adjuvant systemic therapy may be necessary to improve outcome for patients with positive PLC results.

We thank Margaret J. Wheelock (University of Nebraska Medical Center) for reviewing this article.

\section{References}

1. Supjut JH, Hendrix VJ, Ramirez GA, Roper CL. Carcinoma cells in pleural cavity washings. Cancer. 1958;11:1222-5.

2. Eagan RT, Bernatz PE, Payne WS, Pairolero PC, Williams DE, Goellner JR, et al. Pleural lavage after pulmonary resection for bronchogenic carcinoma. $J$ Thorac Cardiovasc Surg. 1984;88:1000-3.

3. Buhr J, Berghauser KH, Morr H, Dobroschke J, Ebner HJ. Tumor cells in intraoperative pleural lavage. An indicator for the poor prognosis of bronchogenic carcinoma. Cancer. 1990;65:1801-4.

4. Okumura M, Ohshima S, Kotake Y, Morino H, Kikui M, Yasumitsu T. Intraoperative pleural lavage cytology in lung cancer patients. Ann Thorac Surg. 1991;51: 599-604.
5. Kondo H, Asamura H, Suemasu K, Goya T, Tsuchiya R, Naruke T, et al. Prognostic significance of pleural lavage cytology immediately after thoracotomy in patients with lung cancer. J Thorac Cardiovasc Surg. 1993;106:1092-7.

6. Kjellberg SI, Dresler CM, Goldberg M. Pleural cytologies in lung cancer without pleural effusion. Ann Thorac Surg. 1997;64:941-4.

7. Okada M, Tsubota N, Yoshimura M, Miyamoto Y, Maniwa Y. Role of pleural lavage cytology before resection for primary lung carcinoma. Ann Surg. 1999; 299:579-84.

8. Lim E, Ali A, Theodrou P, Nicholson AG, Ladas G, Goldstraw P. Intraoperative pleural lavage cytology is an independent prognostic indicator for staging nonsmall cell lung cancer. $J$ Thorac Cardiovasc Surg. 2004;127:1113-8.

9. Mountain CF. Revisions in the international system for staging lung cancer. Chest. 1997;111:1710-7.

10. World Health Organization. The World Health Organization histological typing of lung tumors. 3rd ed. Geneva: The Organization; 1999.

11. The Japan Lung Cancer Society. General rule for clinical and pathological record of lung cancer. 6th ed. Tokyo: Kanehara; 1997. p. 95

12. Kaplan EL, Meier P. Nonparametric estimation from incomplete observations. J Am Stat Assoc. 1958;11:1222-5.

13. Cox D. The analysis of binary data. London: Methuen; 1970.

14. Nakagawa T, Okumura N, Kokado Y, Miyoshi K, Matsuoka T, Kameyama K. Clinical relevance of intraoperative pleural lavage cytology in non-small cell lung cancer. Ann Thorac Surg. 2007;83:204-8.

15. Enatsu S, Yoshida J, Yokose T, Nishimura M, Nishiwaki Y, Shirakusa T, et al Pleural lavage cytology before and after lung resection in non-small cell lung cancer patients. Ann Thorac Surg. 2006;81:298-304.

16. Kotoulas C, Lazopoulos G, Karaiskos T, Tomos P, Konstantinou M, Papamichalis G, et al. Prognostic significance of pleural lavage cytology after resection for non-small cell lung cancer. Eur J Cardiothorac Surg. 2001;20:330-4

17. Ichinose Y, Tsuchiya R, Koike T, Yasumitsu T, Nakamura K, Tada H, et al. A prematurely terminated phase III trial of intraoperative intrapleural hypotonic cisplatin treatment in patients with resected non-small cell lung cancer with positive pleural lavage cytology: the incidence of carcinomatous pleuritis after surgical intervention. J Thorac Cardiovasc Surg. 2002;123:695-9.

18. Satoh Y, Hoshi R, Ishikawa Y, Horai T, Okumura S, Nakagawa K. Recurrence patterns in patients with early stage non-small cell lung cancers undergoing positive pleural lavage cytology. Ann Thorac Surg. 2007;83:197-203. 